2nd International Conference Art, Illustration and Visual Culture in Infant and Primary Education
Blucher Education Proceedings March 2015, Number 2, Volume 1

\title{
El papel de la ilustración en la alfabetización visual
}

Marta Borges marta.cborges@gmail.com

Faculdade de Belas Artes da Universidade do Porto, Portugal

Reference

Borges, Marta; (2012) "El papel de la ilustración en la alfabetización visual", p. 268-272 . In: Barbosa, Helena; Quental, Joana [Eds]. Proceedings of the 2nd International Conference of Art, Illustration and Visual Culture in Infant and Primary Education. São Paulo: Blucher, 2015. ISSN 2318-695X, ISBN: 978-989-98185-0-7 DOl 10.5151/edupro-aivcipe-51

En un período marcado por la reproductibilidad técnica y proliferación de formas diversas de representación gráfica, el desarrollo de la alfabetización visual se asume como una estrategia fundamental para la formación de las personas más informadas y competentes, capaces de comprender e interpretar una realidad más compleja. En esta comunicación, vamos a explorar cómo la ilustración es capaz de constituirse en una herramienta fundamental para el desarrollo de la alfabetización visual. Nos proponemos discutir los vínculos entre la alfabetización visual y el papel (nuevo) de la ilustración, a partir de un estudio de caso: análisis de algunos títulos publicados por Planeta Tangerina (PT). La línea editorial de PT es un buen ejemplo para reflexionar sobre cómo la ilustración se pueden desarrollar nuevas formas de pensar y actuar. Esta comunicación es una investigación en curso, desarrollada en el master en Diseño Gráfico y Proyectos Editoriales de la FBAUP.

Palabras clave ilustración, alfabetización visual, Planeta Tangerina

Abstract

In a period marked by technical reproducibility and the consequent proliferation of multiple graphical forms, the development of visual literacy is a fundamental strategy for the education of informed and competent individuals able to understand and interpret a more complex reality. In this communication, we will explore how can illustration constitute itself as a fundamental tool for the development of visual literacy. We propose to discuss the links between visual literacy and the (new) role of illustration, from a case study: analysis of some titles published by Planeta Tangerina (PT). How will try underline, the editorial line of PT is a good example to reflect on how the illustration can develop new ways of thinking and acting. This communication is an ongoing investigation, developed under the master's degree in Graphic Design and Editorial Projects at Faculty of Fine Arts, University of Porto.

Keywords ilustration, visual literacy, Planeta Tangerina.

\section{Introducción}

En un período marcado por la reproductibilidad técnica y la consiguiente proliferación de la representación de formas distintas de expresión pictórica, el desarrollo de la alfabetización visual se asume hoy como una estrategia fundamental para la comprensión y la interpretación de una realidad cada vez más complejo. En este trabajo, hemos decidido explorar cómo la ilustración puede actuar como una herramienta para el desarrollo de estas habilidades, basada en las ilustraciones que se encuentran en los títulos de la editorial Planeta Tangerina (PT). Este enfoque no pretende ser una revisión exhaustiva del tema, sino más bien un primer vistazo a este tema, lo que permite la identificación de una serie de "pistas" que se pueden desarrollar en los futuros debates. 
2nd International Conference Art, Illustration and Visual Culture in Infant and Primary Education $2^{\circ}$ Congreso Internacional

Arte, Ilustración y Cultura Visual en Educación Infantil y Primaria $2^{\circ}$ Congresso Internacional

de Arte, llustracão e Cultura Visual

na Educação Infantil e Primária

Es en primer lugar, definir lo que queremos designar aquí para ilustración. Este término deriva del latín y significa "medidas para aclarar". M. Isabel Faria y M. Gracia Pericão definir en primer lugar, en su Diccionario del Libro - Del libro electrónico escrito para ilustrar cómo la forma de "iluminar, dar luz a un texto o de un conjunto de textos" (2008:638). En una clara referencia a los manuscritos iluminados medievales de estos autores entienden la ilustración y no como una mera transcripción de un texto, reproduciendo fielmente, sino como una interpretación.

No nos interesa aquí comparar diferentes interpretaciones del concepto de ilustración, en un intento de profundizar en la definición (diferenciando incluso el ejemplo de otras formas de representación visual). Antes de que opte por seguir la definición de Faria y Pericão ilustración teniendo en cuenta todas las representaciones visuales de los "textos" que pueden ir o no, además de la reproducción exacta, siempre que demuestran el significado y/o añadir significado a él.

\section{1. ¿Qué es la alfabetización visual?}

El origen del término alfabetización visual se atribuye a menudo a James Elkins (Gil: 2011, 13) porque ha sido una de las voces más activas en la afirmación de la importancia de desarrollar la alfabetización visual en su "Visual Studies - A Skeptical Introduction" publicado en 2003, la necesidad de incluir los llamados estudios visuales en el currículo académico de las universidades estadounidenses.

Sin embargo, como señala José Manuel Damasio, ya que en 1969 Debes John habría usado la alfabetización visual a largo plazo para definir el conjunto de habilidades que son fundamentales para la comprensión de la realidad y el desarrollo de la comunicación, se puede desarrollar a través de la visión de la asociación a los demás sentidos y experiencias. En este sentido, dijo Debes: "Visual Literacy refers to a group of vision-competencies a human being can develop by seeing and at the same time having and integrating other sensory experiences. The development of these competencies is fundamental to normal human learning. When developed, they enable a visually literate person to discriminate and interpret the visible actions, objects, symbols, natural or man-made, that he encounters in his environment. Through the creative use of these competencies, he is able to communicate with others. Through the appreciative use of these competencies, he is able to comprehend and enjoy the masterworks of visual communication." (Debes apud Avgerinou, s/d).

Por lo tanto, la alfabetización visual se refiere no sólo a la capacidad biológica para ver (Gil, 2011:15), o la capacidad de reconocer una expresión visual como tal (Elkins, 2003:136). La alfabetización visual y no se puede describir como la habilidad para identificar, interpretar y comunicar el contenido específico pictórico y su significado (Elkins, 2003:136; Gil, 2011:15). En este sentido, significa que "persona alfabetizada visualmente es aquel que es capaz de decodificar e interpretar la composición visual, pero también uno que es capaz de codificar y componer imágenes que pueden tener un sentido comúnmente entendido." (Damasio, s/d).

De acuerdo con esta definición, se podría argumentar que la alfabetización visual se compone de tres niveles distintos. La primera se refiere a la capacidad de identificar una expresión visual como tal, el segundo nivel, después de la identificación, se refiere a la capacidad de interpretar. Es este proceso que se evocan experiencias visuales y el conocimiento se construye tan profundamente condicionada por el contexto social, cultural, histórico y político en el que cada individuo pertenece. Y, por último, el tercer nivel se refiere a la capacidad de organizar este nuevo aprendizaje con el fin de, en primer lugar, para aumentar nuestro conocimiento sobre una determinada realidad, y en segundo lugar, para mejorar nuestra capacidad de comunicarnos. Es en este nivel, es claro cómo la alfabetización visual se constituye como una estrategia de desarrollo social, cultural y político, en que el desarrollo de estas habilidades "implica un compromiso activo para hacer preguntas y buscar respuestas a los múltiples significados de experiencia visual."(Morgado, 2009:137).

Es precisamente en el segundo y tercer nivel es evidente por qué la alfabetización visual se debe incluir, como defendió James Elkins (2003), en los programas escolares constituyéndose como un componente clave de la educación. La alfabetización visual implica el dominio de un conjunto de conocimientos previos, la comprensión y la que permite la transmisión de contenido visual. Por lo tanto, estos contenidos deben ser estudiados con el fin de dotar a las personas con habilidades críticas para el ejercicio pleno de la ciudadanía. 
$2^{\text {nd }}$ International Conference Art, Illustration and Visual Culture in Infant and Primary Education $2^{\circ}$ Congreso Internacional

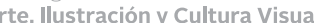
en Educación Infantil y Primaria isso nternacional

de Arte, llustração e Cultura Visual

na Educação Infantil e Primária

\section{La urgencia del desarrollo de la alfabetización visual}

\section{La ilustración y el desarrollo de la alfabetización visual}

Hoy en día nos enfrentamos a una proliferación de diferentes formas de representación gráfica y la expresión. A diferencia de períodos históricos anteriores, donde la cultura era principalmente oral o textual (Elkins, 2003: 131), la mirada contemporánea se ha convertido eminentemente. "We see mode images per month or per year (...) that people on the past; and we can also process more images per minute." (Elkins, 2003:129).

Paradójicamente, esta proliferación de representaciones pictóricas y expresiones que no ha contribuido a la evolución natural de la alfabetización visual, por varias razones. En primer lugar, como se ha señalado, y Gil, "el simple deseo de la experiencia aparece como un antagonista de la voluntad de entender que no sea para disfrutar" (2011:11). Por otra parte, las representaciones de representaciones visuales de complejidad ha dado lugar a más simple. Hoy en día estamos capacitados para "leer" las imágenes y el movimiento simple e inmediata de las imágenes complejas y oscuras del pasado (Elkins, 2003: 134). Los gráficos por ordenador se utilizan ampliamente en los medios como un ejemplo. Estas ilustraciones están diseñadas para "leer" lo más pronto posible, de inmediato su contenido y dejando poco espacio para la interpretación. En muchos casos, estos ejemplos están mucho más eficaz cuanto menor sea el nivel requerido interpretación. Finalmente, cabe señalar que la comprensión y la interpretación de muchas ilustraciones requiere el conocimiento de ciertos códigos. Como señala John Berger, "lo que sabemos o lo que pensamos afecta la forma en que vemos las cosas" (1996: 12). Y por lo tanto también la lectura de imágenes requieren aprendizaje. Martine Joly también advierte del creciente riesgo de ser engañado ya que a menudo están "influenciados, más inconsciente que consciente, algunos iniciados por la experiencia que podemos" manipular "nos sumerge en secreto las imágenes codificadas mediante el aprovechamiento el ingenio de nuestro" (2007:10)

En este contexto, le sigue preocupando que el aumento de la "visual" de la sociedad contemporánea contribuye en cierta medida, para la alfabetización visual. Como la alfabetización visual, como hemos visto, una habilidad esencial para la comprensión de la realidad, se hace evidente la necesidad de fomentar hoy en día esta formal en curso y continua.

El diseño es una poderosa herramienta para la transmisión de conocimiento. Para Manfredo Massironi el diseño es "un instrumento tan simple pero a la vez, tan intrínsecamente elástica que permite la narración, las formas más diversas, de la complejidad." (1982:17).

Muchos ejemplos se producen estrechamente asociado con el texto, hay una clara correspondencia entre el lenguaje verbal y visual (Massironi: 1982, 115). Sin embargo, cuando las ilustraciones no son redundantes a la narrativa y articular con el texto en la producción de significados, estamos viendo una mayor estimulación de la creatividad que contribuye al desarrollo de la alfabetización visual y, en consecuencia, el espíritu crítico.

Para ello, los ilustradores tienen en sus posibilidades de eliminación de numerosas, como se ha señalado por Sophie Van der Linden, "leer un libro de imágenes no es sólo leer el texto y las imágenes (...) también está disfrutando de la utilización de un formato, el marco, la relación entre la cubierta y la guardia con su contenido, sino también las representaciones asociadas, elegir un orden de lectura dentro de la página, ajustar la poesía del texto con la poesía de la imagen, disfrutar del silencio de uno sobre el otro." (2011, 8). Esta manera de ilustrar requiere tiempo y atención a la lectura, pero los puntos que señala Joly, "agudiza el sentido de la observación y mirando a incrementar el conocimiento y por lo tanto permite obtener más información (en su sentido más amplio) en la recepción espontánea de las obras" (2007: 52).

En este contexto, ilustrador y lector de tomar un papel activo en la construcción de significados: el primero establece las pistas de observación y de interpretación de las ilustraciones y la segunda se anima a llenar las "lagunas" en la aprehensión de los significados no sólo son más inmediatos, sino también la construcción de nuevos significados. Por lo tanto, la imagen se convierte en una valiosa herramienta para la enseñanza y el aprendizaje pueden contribuir al desarrollo de la alfabetización visual. 
2nd International Conference Art, Illustration and Visual Culture in Infant and Primary Education $2^{\circ}$ Congreso Internacional

Cultura Visual en Educación Infantil y Primaria
Congresso Internacional

de Arte, Ilustração e Cultura Visual

na Educação Infantil e Primária

\section{El caso de la editorial Planeta Tangerina}

En esta última sección del artículo destaque la Planeta Tangerina (PT), una pequeña editorial portuguesa fundada en 1999. Centrado en la ilustración de libros de publicación, se presentan como un editor que apostar a lo que ellos llaman "formato de álbum - una donde el texto y las imágenes de trabajar juntos (...) la vinculación, completar, hacer ajustes y reajustes, la demanda de equilibrio del conjunto" (Planeta Tangerina, s/d).

El análisis del PT ejemplo es interesante porque las ediciones son un buen ejemplo de la construcción sofisticada de los textos visuales. Las ilustraciones de hacer visibles los conceptos abstractos y complejos, animando al lector a participar activamente en la interpretación del texto y la construcción del conocimiento. En este sentido, como Sophie Van der Linden, los autores también creen que el PT "un álbum es sólo eso: leer no sólo palabras, sino también imágenes, no sólo leer las páginas, pero las secuencias. Lea las cubiertas, guardas, los ritmos y cambios de ritmo, escenas de lectura, planos, detalles, diferentes tipos de representación, haciendo constantemente las conexiones entre los elementos, disfrutando del movimiento, el ruido, las pausas y los silencios de las páginas" (Planeta Tangerina, s/d).

El libro "Todos fazemos tudo" (Madalena Matoso, 2011) es un caso interesante para el análisis, ya que tiene "como un libro tradicional como Meli-Melo", proporcionando una mayor interacción entre el lector y el libro. En un juguetón, PT buscando aquí la promoción de la igualdad de género, utilizando los juegos creados por los ejemplos visuales de formas y colores básicos "en la parte superior de la página se reveló su identidad - si es hombre, si es mujer, ya sea joven o de edad, en la parte inferior para revelar las acciones (...) el lector para adaptarse a las diferentes combinaciones: pasar las páginas es posible cambiar los caracteres y/o actividades y observar cómo, al menos en este libro, no hay prejuicios o ideas hizo". (Planeta Tangerina, s/d).

Otros rasgos que caracterizan a las representaciones gráficas de cualquiera de los ilustradores de PT son las formas se superponen con frecuencia con colores opacos o transparencias. Este enfoque hace que las ilustraciones no son reconocidos e interpretados de inmediato, lo que indica la necesidad de ser revisada. Por ejemplo, señala la publicación "Duas estradas" (Martins e Carvalho: 2009), teniendo dos sentidos de lectura, uno de izquierda a derecha, y una en sentido inverso. Cada lectura corresponde un sentido de la historia en un viaje por separado, que se cruza con la historia de la inversa. Las historias se pueden leer simultáneamente o por separado.

Puente también exigente vista de la lectura en el caso de "Livro dos Quintais" (Martins e Carvalho: 2010), claro ejemplo de la complejidad y el detalle de las ilustraciones, que subyacen a la (re) lectura de modo que, progresivamente, para añadir significado.

Los títulos de las propuestas de algunos de los ES entrar en el campo del significado en la que las ilustraciones se presentan con significados que no estaban previstos originalmente. En el libro "Pê de Pai" (Martins e Carvalho: 2006) hay una serie de asociaciones entre palabras e ilustraciones, que desafían a la lectura de la descodificación de los significados de términos como "freno de padre", "padre de seguridad" o "Padre flecha," por ejemplo. La combinación de texto e imagen se utiliza como un tema a explorar, de manera sutil y muy creativo, la relación de complicidad entre padre e hijo, la desmitificación de la experiencia de haber crecido en familias monoparentales.

De diferentes maneras, pero siempre a través de la ilustración, el texto y el libro como un objeto, los lectores se les anima a pensar críticamente sobre el contenido presente en los álbumes ilustrados de PT. Su línea editorial es, pues, un buen ejemplo para reflexionar sobre el papel de la ilustración en el desarrollo de nuevas habilidades y el estímulo de los lectores (abrigos para niños y jóvenes) a las nuevas formas de pensar y actuar.

En este artículo tratamos de mostrar cómo la ilustración puede operar ya sea en la identificación de las representaciones visuales, ya sea en la interpretación y la construcción de las representaciones más complejas. En el contexto de las sociedades contemporáneas, caracterizadas por la proliferación de la representación de formas distintas de expresión pictórica y, el desarrollo de la alfabetización visual es un elemento clave para la formación de las personas más informadas y competentes. Por ello es importante fortalecer el papel de la ilustración en el contexto de enseñanza-aprendizaje, donde se puede llegar a asumir un papel decisivo, consolidándose como una herramienta para el desarrollo de la alfabetización visual "que nos enseña a hacerlo de otra manera a ser una mirada no ingenua acerca de la complejidad de las fascinantes imágenes que nos rodean." (Gil, 2011:30). 
$2^{\text {nd }}$ International Conference Art, Illustration and Visual Culture in Infant and Primary Education $2^{\circ}$ Congreso Internacional Arte, Ilustración y Cultura Visual en Educación Infantil y Primaria
${ }^{\circ}$ Congresso Internaciona

de Arte, llustração e Cultura Visual

na Educação Infantil e Primária

\section{Referencias bibliográficas}

Avgerinou, Maria. (s.d.). What is "Visual Literacy?. [consulta 28 enero 2012]. Disponible en: <http://www.ivla. org/org_what_vis_lit.htm>.

BERGER, Jonh. (1996). Modos de Ver, col.: Arte \& Comunicação, Lisboa: Edições 70.

COSTA, Joan; MOLES, Abraham. (1991). Imagen Didáctica, Barcelona: Ediciones ceac, S.A.

DAMÁSIO, José Manuel. (s.d.). Contributos para a constituição de uma literacia mediática. [consulta 28 enero 2012]. Disponible en: <http://www.bocc.ubi.pt/pag/_texto.php?html2=damasio-manuelliteracia-mediatica.html>.

DAMÁSIO, José Manuel. (2008-2010). "Literacia Visual” in Dicionário Crítico de Arte, Imagem. Linguagem e cultura. [consulta 28 enero 2012]. Disponible en: <http://www.arte-coa.pt/index.php? Language=pt\& Page=Saberes\&SubPage=ComunicacaoELinguagemlmagem\&Menu2=Autores $\&$ Slide $=41>$.

ELKINS, James. (2003). Visual Studies - A Skeptical Introduction, New York: Routledge.

GIL, Isabel Capeloa. (2011). Literacia Visual - Estudos sobre a inquietude das imagens, col.: Arte \& Comunicação, Lisboa: Edições 70.

JOLY, Martine. (2007). Introdução à Análise da Imagem, col.: Arte \& Comunicação, Lisboa: Edições 70.

LINDEN, Sophie Van der. (2011). Para ler o livro ilustrado, São Paulo: Cosac Naify

MASSIRONI, Manfredo. (1982). Ver pelo Desenho - Aspectos técnicos, cognitivos, comunicativos. Lisboa: Edições 70.

MADUREIRA, Marta. (2010). "Ilustração, breve reflexão sobre uma possível definição" in Book of Abstracts Designa2011, International Design Conference

MARTINS, Isabel Minhós; CARVALHO, Bernardo. (2006). Pê de Pai, Carcavelos: Planeta Tangerina.

MARTINS, Isabel Minhós; CARVALHO, Bernardo. (2009). Duas Estradas, Carcavelos: Planeta Tangerina.

MARTINS, Isabel Minhós; CARVALHO, Bernardo. (2010). Livro dos Quintais, Carcavelos: Planeta Tangerina.

MATOSO, Madalena. (2011). Todos fazemos tudo, Carcavelos: Planeta Tangerina.

MORGADO, Margarida. (2009). "Texto visual/texto cultural. Uma perspectiva de desenvolvimento da literacia visual e intercultural dos jovens" in Anexo dos Congressos 6. ${ }^{\circ}$ SOPCOM/8. ' LUSOCOM. [consulta 28 enero 2012]. Disponible en: < http://conferencias.ulusofona.pt/index.php/sopcom_ iberico/sopcom_ibericoog/paper/view/440/438>.

RANCIĖRE, Jacques. (2011). O Destino das Imagens, Lisboa: Orfeu Negro.

FARIA, Maria Isabel; PERICÃO, Maria da Graça. (2008). Dicionário do Livro - Da escrita ao livro electrónico, Coimbra: Editora Almedina.

Planeta Tangerina (s.d.) sem título.[consulta 28 enero 2012]. Disponible en: <http://www.planetatangerina. com/pt/ola>.

Planeta Tangerina (s.d.). Pê de Pai - Proposta de Exploração para Pais e Educadores. [consulta 28 enero 2012]. Disponible en: < http://www.planetatangerina.com/sites/planetatangerina.com/files/prop_ pai.pdf >

Planeta Tangerina (s.d.). Todos fazemos tudo - Proposta de Exploração para Pais e Educadores Disponible. [consulta 28 enero 2012]. en: <http://www.planetatangerina.com/sites/planetatangerina.com/files/ prop_tft.pdf >.

Planeta Tangerina (2011). sem título. [consulta 28 enero 2012]. Disponible en: <www.planetatangerina.com/ pt/ola>. 